\title{
Root Turnover and Production in Forest Trees
}

\author{
Robert Fogel \\ U niversity of M ichigan Herbarium, N orth U niversity Building, A nn A rbor, M I 48109
}

The prospect of exchanging views and experiences with horticulturists of the American Society for Horticultural Science is very appealing. The boundary between forestry and horticulture is becoming increasingly blurred now that Christmas trees and other woody perennials have become major crops. The recent introduction of molecular genetic and micropropagation techniques has further blurred the distinction. Despite the increasing similarities in the two disciplines, there remain some fundamental differences in our approaches to woody perennials. Horticulture appears to me as an outsider to have taken a tree-centered approach to maximizing productivity, measured as economic fruit yield (Bhat, 1983; Taylor and Ferree, 1981; Tromp, 1983). Forest ecologists interested in production have generally taken an ecosystem approach, often extrapolating results of physiological measurements on single trees to an ecosystem basis. Silviculturists attempt to maximize tree volume. These contrasts may reflect differences in species diversity among the two cropping systems and/or differences in the value of the crops. Although the end result has been different, some of the same methods are used by both disciplines. The newer methods often arise in horticulture and are adapted or reinvented in forestry.

Another difference affecting the approaches used in the two disciplines centers on differences in the structure of root systems and the mycorrhizal symbioses formed that influence the allocation of primary production. I am always struck by the lack of overlapping among apple root systems as depicted by Rogers (1966), and often wonder about the reduced variability that must be present in rootstocks that are genetically identical. In mature forests, the root systems are intertwined and, while genetically identical root stocks exist in clonal species [e.g., bigtooth aspen (Populus grandidentata Michx.)], they too are intertwined and ramets of the same age differ greatly in size due to competition for light.

The type of mycorrhizal symbiosis affects the types of roots formed, their longevity, and thus methods used for sampling roots to estimate net primary production. Nearly all horticultural trees, e.g., apple, avocado, banana, citrus, peach, pear, etc., form mutualistic associations with vesicular-arbuscular mycorrhizal fungi (VAM) for nutrient absorption, as do many forest trees. One exception is Corylus (filbert), which forms ectomycorrhizae, as do many members of the Pinaceae, Fagaceae, Betulaceae, and Salicaceae. The latter form both VAM and ECM associations.

The classical concept of the root tip consisting of a root cap, meristematic zone, elongation zone, and a zone of maturation supporting root hairs is modified slightly in VAM. The fungal symbiont consists of two phases-an internal mycelium within the cortex of the root and an external mycelium spreading through the soil. The basis for the mutualism is the provision of carbohydrate to the fungus in exchange for a more effective system than root hairs for obtaining nutrients. While root hairs may be up to $2000 \mu \mathrm{m}$ long and 10 to $15 \mu \mathrm{m}$ in diameter, they may only persist for 2 to 3 days before being destroyed by microbes (Baylis, 1975; Russell, 1977). Estimates of the quantity of external mycelium of VAM fungi vary from 1.3 to $1.4 \mathrm{~m} \cdot \mathrm{cm}^{-1}$ of infected root length in clover and ryegrass to $0.8 \mathrm{~m} \cdot \mathrm{cm}^{-1}$ in onion (Sanders and Tinker, 1973; Tisdall and Oades, 1979). Hyphal lengths of this magnitude would double the potential absorbing surface of roots 0.5 to $1 \mathrm{~mm}$ in diameter (Gianinazzi-Pearson and Gianinazzi, 1983). Rhoades and Gerdemann (1975) have shown experimentally that the zone of phosphate absorption in VAM plants is greatly expanded beyond the 1- to 2$\mathrm{mm}$ zone explored by root hairs to at least $8 \mathrm{~cm}$ in mycorrhizal onions. Unfortunately, I was unable to find similar data on the extent of extramatrical hyphae associated with woody perennials. The "cost" to the plant of maintaining the VAM association is difficult to estimate, but is assumed to be $\approx 10 \%$ of the fungal biomass, plus carbon respired by the increased metabolic activity of root cells following infection in herbs (Gianinazzi-Pearson and Gianinazzi, 1983). Growth depressions in some VAM herbs have been attributed to host-fungus competition for carbon. The external mycelium of the VAM fungus also provides interplant, even interspecies connections, for direct transfer of carbon, phosphorus, and perhaps other nutrients among neighboring plants (Chiariello et al., 1982; Read et al., 1985; Whittingham and Read, 1982).

In addition to the production lost in supporting the VAM association, VAM species have relatively short-lived, fine roots. Atkinson (1985) reported that, after 4 weeks, apple roots lost their entire cortex. Nearly $75 \%$ of the roots die at this time, but the other $25 \%$ survive to become part of the permanent root system. All apple roots $<1 \mathrm{~mm}$ in diameter die after 4 weeks. This pattern suggests that root turnover and the related investment in photosynthate required for growth and replacement of these roots is high. The proportionally lower investment in roots on nutrient-rich sites than on poor sites, however, may offset this cost to some extent in horticultural cropping systems (Marks et al., 1968).

Ectomycorrhizal associations (ECM) alter the classical concept of the root tip even more profoundly than the VAM symbiosis. In the ECM symbiosis, typified by pine ECM, the classical root is modified by the absence of an epidermis and associated root hairs, the root cap is reduced, and the apical meristem is very small (Harley and Smith, 1983). The result is limited growth producing a 
short root for the association. In addition to anatomical changes in short roots, the classical root is further modified by the presence of a three-phase mycelial system. An internal mycelial network (Hartig net) grows intercellularly around cells of the primary cortex, a sheath or mantle of hyphae covers the entire root surface, and external hyphae extend into the soil. The internal mycelium functions in exchange of materials between fungus and host while hyphae of the mantle, lacking in VAM, act as storage cells, particularly for phosphorus and glycogen (Harley and Smith, 1983). The external mycelium functions in the same manner as the external mycelium of VAM, extending the zone of nutrient absorption and providing connections among plants. An individual hypha may extend $>2 \mathrm{~m}$ from an ECM and form > 120 lateral branches; 200 to > 2000 individual hyphae have been counted emerging from a single ECM (Trappe and Fogel, 1977).

In contrast to VAM, ECM tend to be long-lived, from several months to a reported 13 years (Fogel, 1983). In addition to serving as a storage organ, the ECM mantle may provide some protection against drought (Harley and Smith, 1983). The relatively long life of ECM, coupled with their putative drought-resistance, may provide an advantage for the host over VAM for nutrient absorption on dry, nutrient-poor sites. The cost in maintenance respiration will be higher, however, because more hyphal biomass has to be supported for a longer period.

\section{CONCEPTUAL APPROACH FOR ESTIMATING NET PRIMARY PRODUCTION}

Given the problems in extrapolating detailed physiological studies of gas exchange, etc., to ecosystems as complex as forests, forest ecologists have adopted the harvest approach to estimating net primary production. The need for a more integrative approach than gas exchange has also arisen from the difficulties in isolating root respiration as a component of soil respiration. The method adopted takes several forms, but all are based on measuring differences in biomass on successive sampling dates and correcting for losses. One equation adapted from population dynamics takes the form: $\mathrm{NPP}=\mathrm{B}_{\mathrm{t}+1}-\mathrm{B}_{\mathrm{t}}+\mathrm{L}$, where NPP is net primary production, $\mathrm{B}_{\mathrm{t}}$ is the standing crop at time $t$, and $\mathrm{L}$ is losses, such as tissue lost to herbivory, rhizodeposition, translocation, etc.

Fairley and Alexander (1985) stressed that production estimates derived by this method can be improved substantially if roots can be separated into "live" and "dead" categories rather than using the difference in minimum and maximum standing crops of all roots. Such an approach is often termed "balancing transfers", and permits the calculation of mortality and decomposition rates.

In practice, distinguishing between live and dead roots, except in the most obvious case of unsuberized root tips, is difficult. Fogel (1985) discussed a number of methods that have been used and the problems associated with each. We have recently experimented with a vital stain, fluorescein diacetate (FDA), used to distinguish between metabolically active and inactive fungal hyphae (Soderstrom, 1977), for distinguishing activity among roots. Our experience indicates that the method works well for unsuberized root tips and that differences in the staining intensity of the apical meristem (differences in metabolic activity?) are detectable. However, intact suberized roots and heavily pigmented ectomycorrhizae do not fluoresce. If thin cross sections are examined, however, fluorescence can be detected in suberized roots and pigmented mycorrhizae. Fluorescence of homogenized tissue can also be detected in a fluorometer and might represent a method for screening fine roots and ectomycorrhizae. The method is sensitive enough that if ectomycorrhizae are exposed to dry air for a few minutes they will not fluoresce. Of the available techniques, I believe FDA is the only one that has potential for resolving the problem of distinguishing live roots. The major limitation of the FDA technique is the problem of sampling many roots if they have to be homogenized.

\section{MEASURING PRODUCTION AND TURNOVER}

Various methods are available to measure the standing crops needed for estimating production, mortality, and decomposition. I would like to discuss a few of the problems associated with some of the methods generally employed in forest systems and speculate on the utility of methods that are currently receiving a lot of attention. More information on the methods and some alternative approaches are detailed by Bohm (1979).

\section{Production}

No good methods exist for determining production of large roots $>2 \mathrm{~mm}$ in diameter. The standard approach is to develop speciesspecific allometric equations relating tree diameter to root biomass after several root systems (typically < 10 ) have been excavated hydraulically or mechanically. The standing crop of large tree roots is then calculated by using allometric equations to calculate the biomass of each tree on a study plot by species, and then summing to obtain the standing crop. Production is determined by repeating this procedure once each year and determining production as the difference in successive standing crops. This method does not provide any information on mortality of large roots. The coefficient of variation associated with these estimates typically exceeds $20 \%$.

Soil coring has most often been employed in determining standing crops of fine roots and mycorrhizae. The main drawback of the method is the size of the core relative to scale of spatial heterogeneity in root/mycorrhiza distribution. Bohm (1979) provides some general recommendations for core size in relation to number of replications, sampling design, and the avoidance of compaction in agricultural situations. He recommends that at least five cores, 7 $\mathrm{cm}$ in diameter, are required for good estimates on each sampling date. My experience in mature forests indicates that the coefficient of variation for roots $<2 \mathrm{~mm}$ in diameter from nine cores batched into three samples ranged from $3 \%$ to $16 \%$ in a northern mixed hardwood ecosystem dominated by bigtooth aspen (unpublished data). The coefficient of variation for cores taken on the same dates in a red pine (Pinus resinosa) ecosystem of the same age adjacent to the mixed hardwood ecosystem ranged from $27 \%$ to $34 \%$. The lower variability of the northern hardwood system is probably attributable to many small woody and herbaceous perennials reducing the spatial variability in root distribution compared to the pine system.

The time and labor needed to extract cores ( 4 to $6 \mathrm{hr}$ for 18 cores) is minimal compared to the time needed to separate roots and mycorrhizae from soil. Hand-sorting of roots from cores is commonly employed in studies of forest productivity, but not only is this relatively slow, it has other drawbacks. In my experience, hand-sorting is adequate for roots $>2 \mathrm{~mm}$ in diameter, but wet-sieving is better for recovering fine roots and mycorrhizae (Fogel, 1983). Screen selection for wet-sieving is also important; a $0.53-\mathrm{mm}$ screen retains a third more roots than a 0.91-mm screen (Reynolds, 1970). Bohm (1979) made a similar recommendation. He stated that "separating roots from soil by dry sieving (similar to hand-sorting) should be used only for sandy soils, and its use is limited to tree root studies where roots larger than $2 \mathrm{~mm}$ in diameter are to be investigated. In all other cases washing procedures are to be preferred."

Once the organic matter has been separated from a soil core by wet-sieving, root length can be determined by Newman's line-intersect method (Bohm, 1979). Diameters should also be recorded so that length can be converted to biomass using a length/biomass regression for each size class of roots (Gregory et al., 1978). Alternatively, the number of root/mycorrhiza fragments can be counted in randomly selected squares on a gridded tray and biomass determined by using an independently derived average biomass per fragment conversion factor (Fogel and Hunt, 1979). Root length is an important measurement, because it is used in several nutrient absorption models (Sanders et al., 1983). The increasing availability of digitizing pads, area meters, video digitizing boards, and sophisticated software provides alternatives for measuring and storing data on root length, branching order, volume, etc. (Smucker et al., 1987).

Several direct observation methods have been developed and used extensively in agricultural systems to measure root production. One direct method receiving much attention currently is minirhizotron observation tubes (Taylor, 1987). The complete system consists of an observation tube, a viewing eyepiece or video camera that can be inserted in the tube, stops for selecting preset depths for image recording, recording equipment to store the image permanently, and 
a cart or other device to transport the equipment. Tubes, typically polybutyrate or glass, are inserted into the soil at an angle of $30^{\circ}$ to $45^{\circ}$ to avoid vertical tracking of roots along the tube. Advantages of the method include measurements made in situ on the same roots so that variation in estimates is not subject to the spatial variability encountered in core sampling on successive dates. Photographic or video images are permanent and images can be analyzed by computer. The method is flexible in terms of the number of crops or treatments that can be investigated during one growing season. The disadvantages include root length density being significantly lower at a 0 - to 30-cm depth than the actual density in this zone in the bulk soil (McMichael and Taylor, 1987). Other disadvantages include relatively high values for experimental coefficients of variability that can range from $20 \%$ to $200 \%$; correct tube installation is critical, especially in fine textured soils; and initial cost of instrumentation can range from $\$ 18,000$ to $\$ 25,000$ for a custom-made color video camera system (Brown and Upchurch, 1987; Smucker et al., 1987). In my limited exposure to this method, I believe that there are some additional problems for researchers interested in studying interactions among roots and soil biota. The quality of the images does not seem very high, especially the contrast between suberized roots and the soil. Many soil animals, especially Collembola, appear to be very sensitive to the intensity and/or spectrum of illumination and quickly move away from the light. Many images can be quickly collected, but screening images for those to be analyzed can be a very slow, expensive process. The computer image analysis programs are very powerful and extremely useful for measuring attributes of fine roots, but are not capable of measuring characteristics associated with fungal hyphae, root hairs, or ectomycorrhizae. The covering of the viewing surface by hyphae can be a problem (Smucker et al., 1987). The programming required to resolve structures such as ectomycorrhizae and their associated hyphae is formidable, but must be attempted eventually as production and turnover of ectomycorrhizae use a major share (40\% to $70 \%$ ) of net primary production in forest ecosystems (Fogel, 1985).

Rhizotrons or root observation laboratories represent a second direct observation method. Rhizotrons typically consist of an aboveground entry, with steps leading to a covered walkway separating glass walls on the surface of the soil profile. Two basic types can be distinguished: In the older type, modeled after those built at East Malling, U.K., the observation windows cover intact, native soil profiles. In some of the newer types, the ability to observe root growth in undisturbed soil has been sacrificed to have greater control over experimental conditions. One example of this latter type is the lysimeter rhizotron, consisting of sealed compartments containing porous plates and suction tubes at the bottom of each compartment. Often, the newer types use artificially constructed soils to better control soil texture, increase the number of soil treatments, etc. Many of the same features measured in the minirhizotron method can also be determined in the rhizotron approach. The advantages of the rhizotron include a) better visual access to roots and associated biota, b) better control over lighting conditions, c) fewer problems in reestablishing the bulk density of the soil next to the glass wall, d) higher resolution video or photographic images due to not being constrained by tube diameter or focal length, and e) with the advent of removable windows such as those in our new rhizotron at the Univ. of Michigan Biological Station, the capability to manipulate or sample roots with known histories and then record the resulting changes.

McMichael and Taylor (1987) indicated that some of the disadvantages of the rhizotron approach include: a) cost; b) alteration of the aboveground growing environment; c) higher root density at the glass than in the bulk soil; d) insufficient replication because of the available viewing area; and e) restricted number of compartments, or total number of plants. Other limitations they described included problems presented by the persistence of roots from previous crops and that more than one experiment needs to be run in order to make rhizotrons cost-effective.

Whether these disadvantages pose a serious problem depends on the hypotheses being addressed. The Univ. of Michigan rhizotron was constructed to study interactions among roots and soil biota and how these interactions affect production. The cost of construct- ing this facility in 1987 was $\$ 78,000$, about three times the cost of a minirhizotron system. For the $\$ 78,000$ we have 34 window bays $1.1 \times 1.1 \mathrm{~m}$ containing 16 removable window panes. The result is 116 replicate vertical soil profiles from 0 to $110 \mathrm{~cm}$ in depth and $25 \mathrm{~cm}$ wide, and the area available for observation is equivalent to that provided by 162 minirhizotron tubes $55 \mathrm{~mm}$ in diameter. A $\$ 4000$ video, time-lapse system with a $73-\mathrm{mm}$ macrolens and extension tubes permits recording of time-lapse color images magnified 35 times at a resolution of 350 lines. In addition, we can use a stereomicroscope to examine roots, etc., at up to $\times 50$ magnification. The video system allows us to observe animals as small nematodes and mites, although the legs of smaller mites cannot be visualized. The problem we face is not one of having insufficient area to examine, but of too much area. Damage to the canopy and recolonization of soil disturbed during construction are problems at present, but should decrease as the 70-year-old stand of mixed hardwoods dominated by bigtooth aspen recovers. One enormous benefit already apparent to us is the interaction that occurs among researchers running different experiments. For the types of experiments we plan, the rhizotron method is better than the minirhizotron approach. For experiments requiring replication of sites, the minirhizotron is clearly more cost-effective.

\section{Biomass losses}

Good methods do not exist for determining mortality and decomposition of large roots (Fogel, 1985). As already indicated, the allometric approach does not include dead roots. Large dead roots have been reported in tulip-poplar, apple, and red pine (Fogel, 1985), but it is very difficult to quantify these standing crops. In my experience, we would find large dead roots during hydraulic excavation of aspen root systems, but the force of the water instantaneously destroyed the roots.

Annual loss of fine roots in forest ecosystems ranges from $40 \%$ to $92 \%$ of the standing crop (Fogel, 1985). Losses of this magnitude indicate that fine roots and mycorrhizae are two to five times more important than leaf and branch litter decomposition in returning organic matter to the soil. These losses have been measured by significant differences in the standing crops of roots/mycorrhizae as determined by soil cores. The problems of variability in core data have already been discussed.

Direct observation of roots represents another approach for quantifying these losses. Time-lapse photography not only documents senescence and decomposition, it permits observation at much more frequent intervals than feasible with soil cores. Research on apple indicates that frequent sampling may be required. In research at East Malling, all white roots turned brown after $\approx 4$ weeks and all of the root tissue external to the pericyle was shed (Atkinson, 1985). About $25 \%$ of the extension roots $(\leqslant 2 \mathrm{~mm})$ survived to become part of the structural root system, but all of the finer "lateral" roots were lost soon after browning. The sampling interval for many of the soil coring programs in forests is either seasonal (Vogt et al., 1980) or monthly (Fogel and Hunt, 1983; Persson, 1980). This may not be as great a problem in etomycorrhizal roots given their longer persistence than VAM or non-mycorrhizal roots, but, ideally, one would still like to sample the lateral roots and non-ECM roots present adequately.

Decomposition of fine roots has also been studied by the litterbag technique (e.g., Berg, 1984; Fogel and Hunt, 1979; McClaugherty et al., 1984). In this method, dried, pre-weighed roots are confined in fine mesh bags, subsets collected periodically, and the proportion of original weight remaining determined. I do not believe that this method is as good as direct observation in rhizotrons or minirhizotrons. The chemical quality of the roots used in litterbag studies is variable and probably higher in nitrogen because a large proportion of roots dried and used as the substrate is live. Soil microbes and fauna have to reinvade the roots after burial and may be hindered by the mesh sizes used, initial moisture content of dried substrate, or air pockets. Of perhaps greater significance in nonECM roots is the possibility that the bulk of the root material being "lost" during decomposition or disappearing between core sample estimates of standing crop may actually result from shedding of the primary cortex by the root. An implication of this situation is that 
nematodes and bacteria may be more important than fungi in processing this sloughed material.

\section{CONCLUSIONS}

The importance of root turnover and production plus the associated high costs of maintaining roots have gained increased recognition in both horticulture and forestry, although the approaches to quantifying these changes have been different. Some effort should be made to express results in a common format so that the importance of root processes in different ecosystems or cropping systems can be compared directly. Foresters will have to start reporting root length, for instance, if the utility of nutrient absorption models developed in agriculture is to be evaluated. Similarly, horticulturists could aid comparisons if an ecosystem approach was employed in reporting results of carbon and nutrient allocation in orchards. Atkinson (1985) has made a start by enumerating and evaluating the assumptions that have to be made if root length measurements from rhizotron windows are to be used to calculate root production on an ecosystem basis.

Of the available techniques, minirhizotrons and rhizotrons employing direct observation appear the most attractive. Both of these techniques represent an improvement over soil coring in reduction in variance, frequency of measurement, ease of computer image analysis, and, perhaps most important, in minimizing disruption of spatial relationships of roots and associated rhizosphere biota. The extent of sloughing of cortical material after root browning and the role of soil biota in processing this material represent one area where direct observation may increase our understanding of the factors affecting root production and turnover. Another area is the importance of faunal grazing of mycorrhizal hyphae and roots in decreasing nutrient absorption by the plant.

\section{Literature Cited}

Atkinson, D. 1985. Spatial and temporal aspects of root distribution as indicated by the use of a root observation laboratory, p. 43-66. In: A.H. Fitter, D. Atkinson, D.J. Read, and M.B. Usher (eds.). Ecological interactions in soil. Spec. Publ. Ser. Brit. Ecol. Soc. 4. Blackwell Scientific, Oxford, U.K.

Baylis, G.T.S. 1975. The magnolioid mycorrhiza and mycotrophy in root systems derived from it, p. 373-389. In: F.E. Sanders, B. Mosse, and P.B. Tinker (eds). Endomycorrhizas. Academic, New York.

Berg, B. 1984. Decomposition of root litter and some factors regulating the process: long-term root litter decomposition in a Scots pine forest. Soil Biol. Biochem. 16:609-617.

Bhat, K.K.S. 1983. Nutrient inflows into apple roots. Plant \& Soil 71:371380.

Böhm, W. 1979. Methods of studying root systems. Springer-Verlag, Berlin.

Brown, D.A. and D.R. Upchurch. 1987. Minirhizotrons: A summary of methods and instruments in current use, p. 15-30. In: H.M. Taylor (ed.). Minirhizotron observation tubes: Methods and applications for measuring rhizosphere dynamics. Amer. Soc. Agron., Madison, Wis. Spec. Publ. 50 .

Chiariello, N., J.C. Hickman, and H.A. Mooney. 1982. Endomycorrhizal role for interspecific transfer of phosphorus in a community of annual plants. Science 217:941-943.

Fairley, R.I. and I.J. Alexander. 1985. Methods of calculating fine root production in forests, p. 37-42. In: A.H. Fitter, D. Atkinson, D.J. Read, and M.B. Usher (eds.). Ecological interactions in soil. Spec. Publ. Ser. Brit. Ecol. Soc. 4. Blackwell Scientific, Oxford, U.K.

Fogel, R. 1983. Root turnover and productivity of coniferous forests. Plant \& Soil 71:75-85.

Fogel, R. 1985. Roots as primary producers in below-ground ecosystems, p. 23-36. In: A.H. Fitter, D. Atkinson, D.J. Read, and M. Usher. Eco- logical interactions in soil. Brit. Ecol. Soc. Spec. Publ. 4. Blackwell Scientific, Oxford.

Fogel, R. and G. Hunt. 1979. Fungal and arboreal biomass in a western Oregon Douglas-fir ecosystem: distribution patterns and turnover. Can. J. For. Res. 9:245-256.

Gianinazzi-Pearson, V. and S. Gianinazzi. 1983. The physiology of vesicular-arbuscular mycorrhizal roots. Plant \& Soil 71:197-209.

Gregory, P.J., M. McGowan, P.V. Biscoe, and B. Hunt. 1978. Water relations of winter wheat: 1 . Growth of the root system. J. Agr. Sci., (Cambr.) 91:91-102.

Harley, J.L. and S.E. Smith. 1983. Mycorrhizal symbiosis. Academic, London.

Marks, G.C., N. Ditchburne, and R.C. Foster. 1968. Quantitative estimate of mycorrhiza populations in radiata pine forests. Austral. For. 32:2638 .

McClaugherty, C.A., J.D. Aber, and J.M. Melillo. 1984. Decomposition dynamics of fine roots in forested ecosystems. Oikos 42:378-386.

McMichael, B.L. and H.M. Taylor. 1987. Applications and limitations of rhizotrons and minirhizotrons, p. 1-14. In: H.M. Taylor (ed.). Minirhizotron observation tubes: Methods and applications for measuring rhizosphere dynamics. Amer. Soc. Agron., Madison, Wis., Spec. Publ. 50.

Persson, H. 1980. Spatial distribution of fine-root growth, mortality and decomposition in a young Scots pine stand in Central Sweden. Oikos 34:77-87.

Read. D.J., R. Francis, and R.D. Findlay. 1985. Mycorrhizal mycelia and nutrient cycling in plant communities; p. 193-217. In: A.H. Fitter, D. Atkinson. D.J. Read. and M.B. Usher (eds.). Ecological interactions in soil. Spec. Publ. Ser. Brit. Ecol.. Soc. 4. Blackwell Scientific, London.

Reynolds, E.R.C. 1970. Root distribution and the cause of its spatial variability in Pseudotsuga taxifolia (Poir.) Brit. Plant Soil. 32:501-517.

Rhoades, L.H. and J.W. Gerdemann. 1975. Phosphate uptake zones of mycorrihizal and non-mycorrhizal onions. New Phytol. 75:555-581.

Rogers, W.S. 1966. The roots of fruit trees, J. R. Hort. Soc. 91:198-205.

Russell, R.S. 1977. Plant root systems: Their function and interaction with the soil. McGraw-Hill, London.

Sanders, F.E., J.G. Buwalda, and P.B. Tinker. 1983. A note on modeling methods for studies of ectomycorrhizal systems. Plant \& Soil 71:507512 .

Sanders, F.E. and P.B. Tinker. 1973. Phosphate flow into mycorrhizal roots. Pesticide Sci. 4:384-395.

Smucker, A.J.M., J.C. Ferguson, W.P. DeBruyn, R.L. Belford, and J.T. Ritchie. 1987. Image analysis of video-recorded plant root systems, p. 67-80. In: H.M. Taylor (ed.). Minirhizotron observation tubes: Methods and applications for measuring rhizosphere dynamics. Amer. Soc. Agron., Madison, Wis. Spec. Publ. 50.

Soderstrom, B.E. 1977. Vital staining of fungi in pure cultures and in soil with fluorescein diacetate. Soil Biol. Biochem. 9:59-63.

Taylor, B.H. and D.C. Ferree. 1981. The influence of summer pruning on photosynthesis, transpiration, leaf abscission, and dry weight accumulation of young apple trees. J. Amer. Soc. Hort. Sci. 106:389-393.

Taylor, H.M. (ed.). 1987. Minirhizotron observation tubes: Methods and applications for measuring rhizosphere dynamics. Amer. Soc. Agron. Spec. Publ. 50.

Tisdall, J.M. and Oades, J.M. 1979. Stabilization of soil aggregates by the root systems of ryegrass. Austral. J. Soil Res. 17:429-441.

Trappe, J.M. and R. Fogel. 1977. Ecosystematic functions of mycorrhizae, p. 205-214. In: J.K. Marshall (ed.). The belowground ecosystem: A synthesis of plant-associated processes. Colorado State Univ., Fort Collins. Range Sci. Dept. Sci. Ser. 26.

Tromp, J. 1983. Nutrient reserves in roots of fruit trees, in particular carbohydrates and nitrogen. Plant \& Soil 71:401-413.

Vogt, K.A., R.L. Edmonds, C.C. Grier, and S.R. Piper. 1980. Seasonal changes in mycorrhizal and fibrous-textured root biomass in 23- and 180year-old Pacific silver fir stands in western Washington. Can. J. For. Res. 10:523-529.

Whittingham, J. and D.J. Read. 1982. Vesicular-arbuscular mycorrhizas in natural vegetation systems: III. Nutrient transfer between plants with mycorrhizal interconnections. New Phytol. 90:277-284. 